
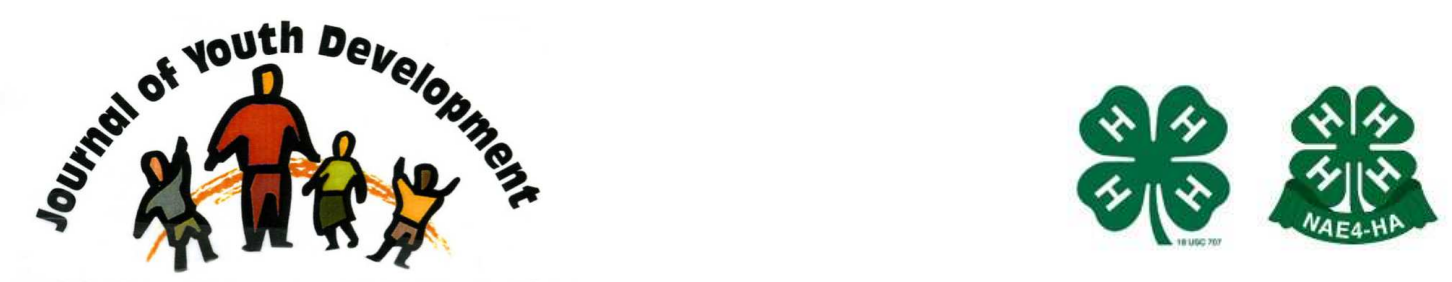

Bridging Research \& Practice

\title{
Measuring Positive Youth Development: The Development of a State Benchmark
}

\author{
Robert J. Nystrom \\ Office of Family Health \\ Oregon Department of Human Services \\ Portland, OR \\ Adriana Prata \\ Office of Family Health \\ Oregon Department of Human Services \\ Portland, OR \\ Sarah Knipper Ramowski \\ Office of Family Health \\ Oregon Department of Human Services \\ Portland, OR \\ sarah.ramowski@state.or.us
}




\title{
JOURNAL OF YOUTH DEVELOPMENT \\ bridging research and practice

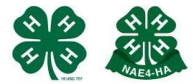

Volume 3, Number 1, Summer 2008

Article 080301FA002

\section{Measuring Positive Youth Development: The Development of a State Benchmark}

\author{
Robert J. Nystrom, Adriana Prata and Sarah Knipper Ramowski \\ Oregon Department of Human Services
}

\begin{abstract}
Public health benchmarks are indicators for well-being and health status that help inform program planning and policy development. In Oregon, recent efforts by a group of state agencies and community partners led to the adoption of a Positive Youth Development (PYD) benchmark by the Oregon Progress Board in 2006. In this paper, we describe the process of creating the state benchmark and present research evidence showing strong relationships that link high levels of PYD to reduced levels of risk behaviors and increased levels of positive, healthy behaviors among Oregon youth. The creation of this benchmark allows better planning, development and monitoring of PYD programs by state agencies, schools and community partners. In addition, results reinforce the finding that the promotion of programs that boost one or more elements of PYD may help reduce risky behaviors and improve positive, healthy behaviors among adolescents.
\end{abstract}

\section{Introduction}

Youth development research has historically been presented and discussed under several different monikers - prevention science, risk and protective factors, developmental assets, and resiliency to name a few. The majority of this research focuses on the degree to which certain factors (individual, attitudinal, familial, social and environmental) are related to healthy development and the manifestation or mitigation of risk behaviors among youth (Resnick, Bearman, Blum, et al., 1997; Resnick, Harris \& Blum, 1993; Roth \& Brooks-Gunn, 2003). The literature contains several different definitions for what constitutes "positive youth development" (PYD) and how it may impact youth.

In this paper, we present Oregon's efforts to define and adopt a state benchmark for PYD. No standard definition of PYD exists; here we use a comprehensive definition of PYD to mean supports, services and/or skills that promote healthier youth attitudes and abilities. Our 
working definition reflects the broad theoretical and strength-based principles, thinking or knowledge base within the ongoing evolution of the field of Positive Youth Development.

Throughout 2005, a group of state agencies and community partners met and developed a measure for PYD. The measure consisted of six questions included on the Oregon Healthy Teens (OHT) Survey, the state's annual health survey of youth in $8^{\text {th }}$ and $11^{\text {th }}$ grades. The six individual questions were asked on the 2006 statewide survey, and results were analyzed in order to create a unique PYD measure and adopt a state PYD benchmark. Finally, the Oregon Progress Board (an independent state planning and oversight agency) adopted the benchmark at the end of 2006.

We start by discussing previous efforts and frameworks for benchmarking in general, as well as Oregon's efforts to develop benchmarks in order to plan, implement and monitor public health programs that benefit adolescents. Second, we review the development and current state of PYD literature and discuss how our measurement constructs were derived from PYD mainstream theory. We then present the methodology employed for the choice and refinement of measures, and the first data collection efforts and results. And finally, we analyze the data.

Given PYD theory as described in detail in the literature review, we expected that, if our measures are valid, we should find strong associations linking high levels of PYD to small levels of risk behaviors and high levels of positive, healthy behaviors. We selected ten major health behavior areas, such as nutrition, physical activity, substance use, and grade performance, and analyzed the association between PYD and health behaviors; results fully validated our expectations. We then presented the creation of three alternative state PYD benchmark measures, tested the three benchmarks against the various health areas, and justified the final choice of the benchmark. We conclude by discussing the policy implications of the newly adopted PYD Oregon state benchmark.

\section{History of Oregon Benchmarking}

Numerous frameworks for the development, publication and use of statistical indicators of the health status and well being of populations are in use in the United States and abroad. Healthy People 2010, the U.S. Department of Health and Human Services' comprehensive, nationwide health promotion and disease prevention agenda is a well-known example of such an effort (2005). Indicators of health status are attracting attention among officials at all levels of government as well as among the private-sector executives making decisions about such issues as where to locate or relocate operations and the availability, education and health of their prospective workforce (Alaska Division of Public Health, 2006; Johnston, Wheeler, Deuser, et al., 2000; Metzler, 2006).

The state of Oregon began in 1989 to devise indicators of well being, calling them benchmarks, which started as part of a long-term project and strategic plan (Oregon Shines) to improve the economy of the state initiated by then-governor Neil Goldschmidt. The introduction of the benchmarks in 1990 included targets for 2000 and 2010 for such health indictors as infant mortality, childhood immunization, teen pregnancy, and youth substance abuse along with others related to jobs, economy and environmental quality. The Oregon Progress Board (OPB), a public body whose members are community, business, and government leaders, was created by the state legislature to manage the benchmarking process. In 2001, under the leadership of Governor John Kitzhaber, the legislature acted on making the board a permanent part of state 
government, moving it into the state's central administrative department and giving it responsibility for developing state agency performance guidelines.

Oregon has experienced both the success and failure of benchmarking. Over time, individual benchmarks have been added, deleted or revised and continue to be refined along with the system of reporting results. In 1993 there was a high of 273 benchmarks that were attempted to be monitored. For the 2005-2007 biennium, 90 benchmarks were followed within the categories of Economy, Education, Civic Engagement, Social Support, Public Safety, Community Development and Environment. The effort demonstrates that although benchmarking (or any other use of indicators) can bring health problems into better focus, it cannot cause problems to be solved. Indicators are tools that can be used to inform policy and support or stimulate locallevel change; they are not substitutes for effective policymaking.

Despite its challenges, Oregon's strategic planning approach to public health, using a comprehensive, statewide process and societal-level indicators of well being, is widely recognized as an innovative, successful program, having won a prestigious innovation award from the Kennedy School of Government (Oregon Department of Administrative Services, 2002). One of the factors that distinguished the Oregon process from similar data-gathering efforts in other states at the time is its comprehensiveness. Health indicators were considered an integral part of a broad system, based on outcomes, of monitoring progress toward a desirable future. Good health is essential to a wide range of Oregon's goals, including a strong economy and safe, caring communities.

In 2005, Oregon continued its penchant for innovation and began looking at the feasibility of developing a statewide PYD benchmark for school-aged youth utilizing the Oregon Healthy Teens Survey as the primary surveillance tool. This effort grew out of a synthesis of common interest among three state agencies: the Oregon Progress Board, State Public Health Division (Adolescent Health), and the Oregon Commission on Children \& Families. The Progress Board had recognized that their intended 'well-being' (benchmark) measures for school-aged youth typically only represented risk factors or negative behaviors (e.g. tobacco use, alcohol use, unintended pregnancy, suicide) and had discussed wanting to adopt a 'positive' measure for youth. Adolescent Health recognized that PYD and its emerging evidence base and growing national recognition represented an important conceptual framework for the design of statewide adolescent health programs. However, there was no state-level surveillance data to help establish the relationship between PYD and those important public health issues typically defined only by risk behaviors. The Commission had an active PYD program in some counties funded by a grant effort and was trying to put a stronger state-level framework supporting the integration of PYD into public policies and practices.

\section{Literature Review: Positive Youth Development}

Positive Youth Development formally emerged as an alternative approach to reducing problem behaviors in youth during the early 1990's. However, its roots date back to the early 1970's when the first research on the concept of resiliency emerged. Werner and Smith (1977) published a groundbreaking longitudinal study documenting the positive effects of certain internal and external factors on "high-risk" youth (e.g., those experiencing family instability, poverty) as they developed into adults. A combination of four factors distinguished those that experienced positive outcomes from those who were impacted by teen pregnancy, health issues, and violence: an easy-going nature, strong language and analytical skills, having a social network and outside interests, and a close connection to a parent or other role model. These 
were deemed "resiliency" factors. This was the precursor to a formal shift in thinking from exclusively treatment to problem prevention, an effort that took hold in the early 1970's. At this stage, much of the focus was on single-issue prevention (i.e., juvenile crime, alcohol use, drug use, etc.).

During the 1980's, however, this single focus strategy was coming under pressure as research emerged that many of these behaviors were interconnected not only with each other but also with other social and environmental factors. Building on Werner \& Smith, the concept that some factors protected against risk (e.g., connectedness to school) and others increased one's susceptibility to risk (i.e., single-parent household) among youth was cemented in the early 1990's in several different studies (Coie, Watt, et al., 1993; Hawkins, Catalano and Miller, 1992; Resnick, Harris \& Blum, 1993). The concept of connectedness has been shown to be especially protective against negative outcomes, even overruling negative factors such as unstable family composition (Hawkins, Catalano and Miller, 1992).

The positive effects of a high level of connectedness among youth has been shown to have lasting effects, even four years later, reducing risk behaviors and negative outcomes (Scales, Benson, \& Mannes, 2006). This framework of risk and protective factors emerged as the backbone of PYD theory (Bernat \& Resnick, 2006). Many of the protective factors that were highlighted in the risk/protective literature are also reflected in PYD. There is a saying in the field - "Problem-free is not fully prepared" - that reflects the idea that simply preventing behaviors by minimizing risk factors is not sufficient to raise healthy youth. Instead, it is extremely important to focus on encouraging and promoting those positive, protective factors that have been demonstrated to be associated with better outcomes for youth. This investment in youth "developmental nutrients" is associated with better outcomes both in the present and future (Benson, Scales, Hamilton, et al, 2006).

There is ample evidence that youth who possess a few or more of these protective factors can overcome negative risk factors to prevail with positive outcomes. The exact mechanics of this seem to vary and are as yet unknown. But the literature does suggest that even youth who are characterized by multiple risk factors will be far less prone to be involved with violence if they also have protective factors such as adult connectedness and spirituality (Resnick, Bearman \& Blum, 1997).

The literature contains many articles written about specific youth factors, whether framed as risk and protective factors, PYD characteristics, or simply desirable and undesirable behaviors (Boles, Biglan \& Smolkowski, 2006.). As described in the methods section, however, Oregon's research effort decided on six questions that represent five Positive Youth Development constructs to measure among $8^{\text {th }}$ and $11^{\text {th }}$ graders. The five constructs are:

1. competence (belief in individual ability to do something well),

2. confidence (feeling of empowerment and control over the future),

3. health (self-reported physical and emotional health status),

4. support (caring relationship with teacher or other adult), and

5. service (volunteering in community).

The practical reasons for this choice are described later. The scientific basis for these choices, however, is widely supported in the literature. 
One of the main issues in making this type of decision is narrowing down the list of potential variables to consider, since there is evidence to support many different potential measures. This dilemma is common to most research focusing on this area (Carter, Spitalny, \& Marsh, et al., 2006; Sabaratnam \& Klein, 2006). The literature is supportive of a number of PYD, or protective, factors as being potentially protective against risk behaviors and helpful in supporting positive behaviors. (Roth, Brooks-Gunn, Murray, et al., 1998) In a review of evaluations of PYD programs deemed effective, Catalano, Berglund, Ryan, et al. (2004) developed a list of 14 PYD constructs that various effective programs were found to have promoted. The constructs include different elements of promoting competence (e.g., social, moral, emotional), fostering a sense of self-determination, providing recognition for positive behavior, and providing opportunities for pro-social involvement. In other research, PYD constructs are described along five or six levels: Competence, Confidence, Connections, Character, Caring and Contribution (Roth \& Brooks-Gunn, 2003; Nicholson, Collins \& Holmer, 2004). This is very similar to the constructs chosen for this particular study.

Recently, Boles, Biglan \& Smolkowski (2006) have completed research that questions the strength of association between levels of PYD and better youth outcomes. This research must be given special consideration by the authors of this paper because it draws on the same data source - Oregon Healthy Teens - as the one used here. Boles, et al. found that negative behaviors are more likely to co-occur with other negative behaviors than positive behaviors are with the absence of negative behaviors. However, positive behaviors were shown to be associated with lesser risk in some areas of substance use and antisocial behavior. Based on their data, Boles and his colleagues asserted, "efforts to promote PYD may have limited impact in preventing youth problem behaviors." However, Boles' exclusive focus on items that measure behavior leaves out several important dimensions of PYD such as attitudes/beliefs, connectedness and self-perceived health status. Only one of the positive factors used by Boles was also chosen in this study as a PYD construct: volunteering in the community. Their work reminds us of the inherent difficulties in any effort attempting to measure or characterize the full breath of PYD with a narrow selection of indicators.

The other major consideration in selecting measures for a statewide benchmark is practicality. To our knowledge, the only other state that has attempted to create a PYD measure to be used at the state level is New York (Surko, Pasti, et al.; 2006). Attempting to create a measure, or series of measures, that will have utility as a practical public health measure brings up additional considerations beyond what is most scientifically valid. Researchers and contributors to the New York State effort cite measurability, consensus building and a general education effort of involved partners as being important factors to consider when developing statewide indicators.

Positive youth development may mean different things to different people, and the process of selecting indicators must have some sort of general buy-in from stakeholders (Sabaratnam and Klein, 2006). Oregon's effort benefited from already having the data collection tool available to us (the state's adaptation of the Youth Risk Behavior Surveillance survey), but we also had to gain permission from survey stakeholders to add questions to the survey that would satisfy the PYD construct while still fitting in with the rest of the survey. Our six measures were selected based on both the in-depth literature discussed here and the very practical considerations necessary to state government operations. In the end, we felt our selections were highly rooted and supportable by the available research on PYD and risk/protective factors. 


\section{Choosing PYD Indicators and Collecting Data}

Throughout 2005, a group of partners (representing the Oregon Progress Board, the Oregon Commission on Children and Families, the Washington County Commission on Children \& Families, the Oregon Department of Human Services Office of Disease Prevention and Epidemiology, Center for Health Statistics, and the Office of Family Health, Adolescent Health Section) interested in developing a method of measuring PYD in Oregon met and discussed the choice of questions that could be included on the OHT survey for this purpose. OHT is a comprehensive, anonymous and voluntary survey that monitors risk behaviors and other factors that affect the physical and emotional health and well being of adolescents (online at www.dhs.state.or.us/dhs/ph/chs/youthsurvey/index.shtml). Each year, the survey is administered to a sample of randomly selected high schools and middle schools in Oregon. In odd-numbered years the sample selection methodology meets the Centers for Disease Control and Prevention criteria for their Youth Risk Behavior Survey. Data collected by OHT are a key source of state and national leading health indicators and outcome measures, such as those included in the Oregon Legislative Benchmarks and Healthy People 2010.

Discussions and decision-making around the choice of PYD questions on the OHT survey were guided by a few considerations:

1. There are very real practical limitations regarding adding new questions to the survey, thus there was substantial value in using or modifying questions that were already on the survey or have been asked in the past;

2. The choice of indicators would be in agreement with or reflect PYD frameworks or measurement constructs currently represented in the literature; and

3. While there is a rapidly growing national interest in PYD measurement and evaluation, there is currently no national consensus on any single theoretical framework to define PYD or likewise any single recommended measurement.

The group reviewed literature and discussed research related to PYD frameworks and measurement. Based on extensive discussions the group developed and adopted a conceptual framework that would guide question development and adoption. The conceptual framework had two major measurement dimensions - individual and environmental - that represented five commonly recognized components of PYD summarized below in Table 1 . The final questions are displayed below in Table 2 .

Table 1

Conceptual framework for developing PYD measurement tools

\begin{tabular}{|c|c|c|}
\hline Dimension & PYD Component & Component Description \\
\hline Individual & Competence & Belief in individual ability to do something well \\
\hline Individual & Confidence & Feeling of empowerment and control over the future \\
\hline Individual & Health & Physical, emotional or mental health \\
\hline Environmental & Support & Connectedness to family and the school community \\
\hline Environmental & Service & Engagement in the community \\
\hline
\end{tabular}


Table 2

PYD Question Wording

\begin{tabular}{|c|c|c|}
\hline PYD Component & Question & Answer Choices \\
\hline Health & $\begin{array}{c}\text { "In general, would you say your } \\
\text { [physical/emotional] health is...?" }\end{array}$ & Excellent, Very good, Good, Fair, Poor \\
\hline Competence & "I can do most things if I try." & $\begin{array}{c}\text { Very much true, Pretty much true, A } \\
\text { little true, Not at all true }\end{array}$ \\
\hline Confidence & "I can work out my problems." & $\begin{array}{c}\text { Very much true, Pretty much true, A } \\
\text { little true, Not at all true }\end{array}$ \\
\hline Support & $\begin{array}{c}\text { "There is at least one teacher or other } \\
\text { adult at my school that really cares } \\
\text { about me." }\end{array}$ & $\begin{array}{c}\text { Very much true, Pretty much true, A } \\
\text { little true, Not at all true }\end{array}$ \\
\hline Service & "I volunteer to help others in my \\
community." & Very much true, Pretty much true, A \\
little true, Not at all true
\end{tabular}

A matrix was developed that compiled past and current questions that have been used on YRBS/OHT that related to PYD frameworks and which were grouped to represent the above conceptual framework. Principal component analysis was conducted on 2004 OHT data to help identify individual questions that accounted for the majority of variance across the components. Multiple principal component analyses were conducted so that a question could be chosen for each of the six conceptual dimensions. For example, in order to choose a question that measured best connectedness to family and to the school community, six different questions were included in the principal component analysis and reduced to one question or measure to be included in the survey. As a result, the number of questions was reduced to six; these six questions were included on the 2006 OHT survey and administered to 3,615 eight grade and 2,602 eleventh grade students from randomly selected Oregon secondary schools. The distribution of answers for each question is presented below in figures 1 through 5.

Figure 1

Physical Health \& Mental and Emotional Health (2 questions)

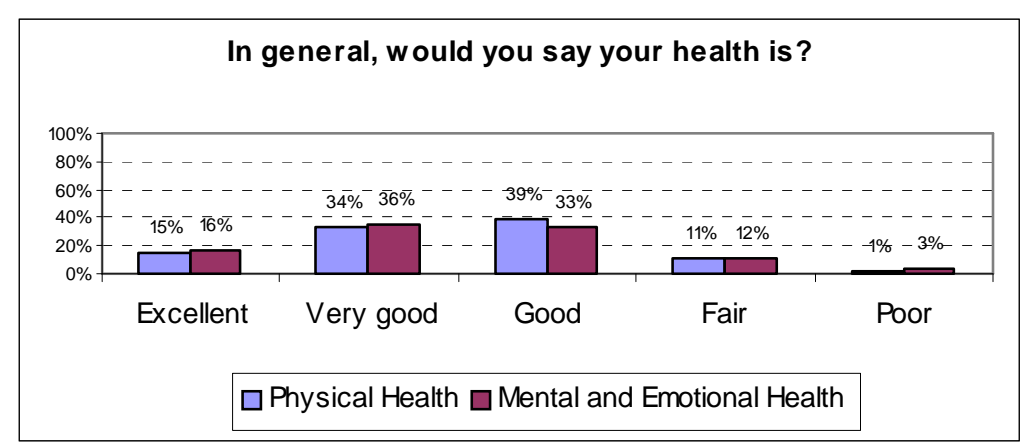


Figure 2

Confidence

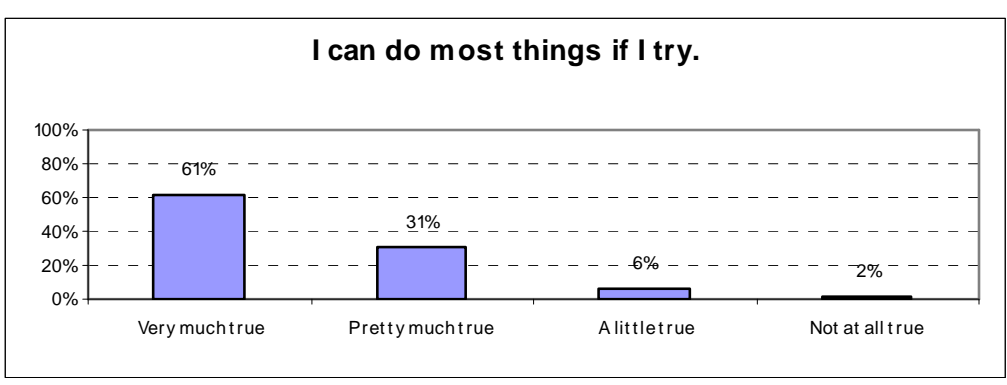

Figure 3

Support in the school environment

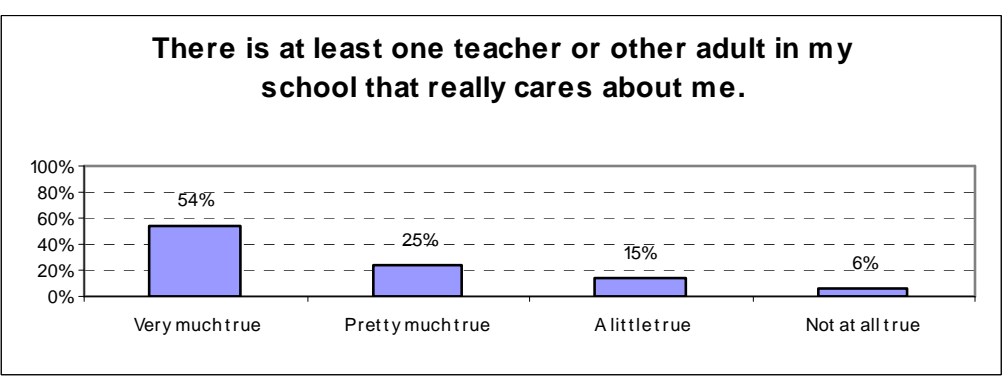

Figure 4

Service to the community

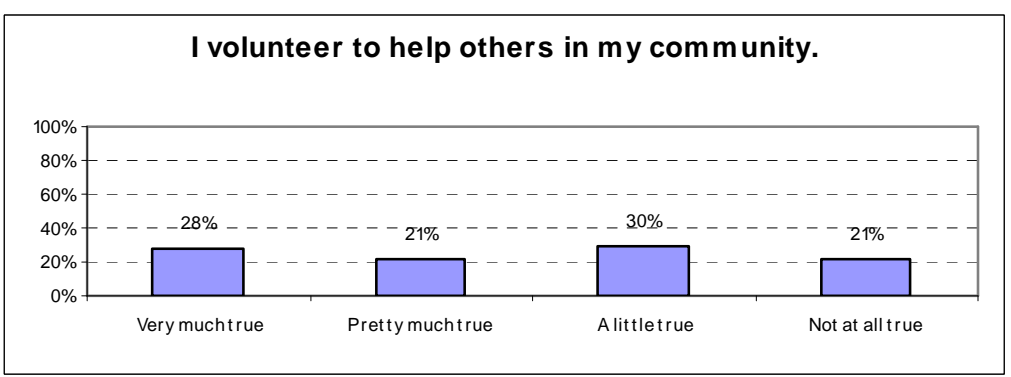

Figure 5

\section{Competence}

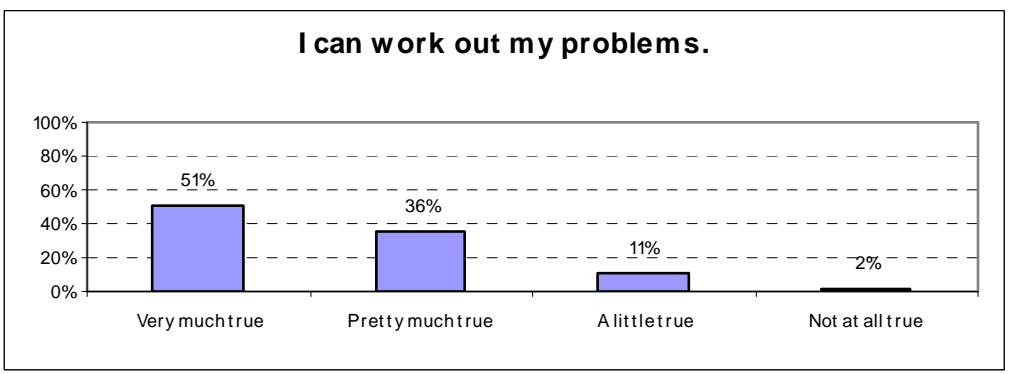




\section{Analyzing the Individual Questions}

Our analysis of the six individual questions began by testing the relationship between levels of risk behaviors and levels of PYD. Given the mainstream theory of the strong connection between individual health risk behaviors and levels of PYD, we expected that if the measures effectively capture PYD, we should find a strong association linking high levels of PYD to small levels of risk behaviors and to high levels of positive, healthy behaviors.

Questions were selected from the following health areas: nutrition, physical activity, suicide, sexual behaviors, tobacco, alcohol and drug use, grade performance, suspension from school and physical fighting. Two-way tables with tests of associations were produced, using weighted data for each of the 6 PYD questions against each of these health behavior areas. (The 2006 OHT sampling methodology was a random sampling of statewide high schools and middle schools, with no prior stratification; thus data are weighted using the statewide probability weight, as well as a primary sampling unit variable that accounts for clustering and uniquely identifies each school.) The strength of association between variables was analyzed using $x 2$ tests with Rao-Scott corrections in Stata (all p-values reported in the paper are based on corrected Rao-Scott $\times 2$ statistics).

Logistic regression was not employed in the analysis. Chi-squared tests are a special case of logistic regression. Logistic regression assumes a dependent variable, and one or more independent variables. With $\mathrm{X} 2$ tests, there is no assumption about independent and dependent variables: the tests simply measure association. Our analysis is aimed at measuring the strength of association between levels of PYD and risk or positive health behaviors, rather than measure effect and cause. In fact, we acknowledge that the direction of causality can go both ways: increases in a student's PYD level may reduce the risk of negative behaviors and boost the likelihood of positive health behaviors; and at the same time, positive changes in health behaviors may increase a student's PYD level.

Results provided strong evidence that students with higher levels of PYD are less likely to incur health behavior risks and more likely to adopt healthy, positive behaviors. At both the $8^{\text {th }}$ and $11^{\text {th }}$ grade levels, students that report strong levels of PYD are more likely to:

$>$ Have had at least 3 servings of fruits and vegetables a day during the past 7 days;

$>$ Have been physically active at least 3 days a week for 60 minutes or more during the past 7 days;

$>$ Have not seriously considered suicide during the past 12 months;

$>$ Have never had sexual intercourse;

$>$ Have not smoked tobacco at all during the past 30 days;

> Have not used marijuana, inhalants, prescription drugs, stimulants, cocaine, heroin, ecstasy and/or LSD during the past 30 days;

> Have not consumed any alcohol during the past 30 days;

> Have never been suspended from school during the past 12 months;

$>$ Have never been involved in a physical fight during the past 12 months;

$>$ Have mostly A and B grades. 
Table 3 below contains a matrix with the statistical significance levels indicating the strength of the relationship between each PYD question and each risk behavior. The stronger the relationship, the less likely are students that indicated higher levels of PYD to incur risk behaviors and the more likely to have healthy positive behaviors.

Table 3

Levels of Statistical Significance for the Relationship between PYD and Health Risk Behaviors

\begin{tabular}{|c|c|c|c|c|c|c|c|c|c|c|c|c|}
\hline & \multicolumn{2}{|c|}{$\begin{array}{c}\text { Physical } \\
\text { health }\end{array}$} & \multicolumn{2}{|c|}{$\begin{array}{l}\text { Mental } \\
\text { health }\end{array}$} & \multicolumn{2}{|c|}{ Confidence } & \multicolumn{2}{|c|}{ Support } & \multicolumn{2}{|c|}{ Service } & \multicolumn{2}{|c|}{ Competence } \\
\hline & 8th & 11th & 8th & 11th & 8th & 11th & 8th & 11th & 8th & 11th & 8th & 11th \\
\hline Nutrition & $* * *$ & $* * *$ & $* * *$ & $* *$ & $* * *$ & ** & $* * *$ & $* *$ & $* * *$ & $* * *$ & $* * *$ & ** \\
\hline Physical Activity & $* * *$ & $* * *$ & $* * *$ & $* * *$ & $* * *$ & $* * *$ & * & - & * & $* * *$ & $* *$ & $* * *$ \\
\hline Suicide & $* * *$ & $* *$ & $* * *$ & $* * *$ & $* * *$ & * & $* * *$ & $* *$ & $* * *$ & - & $* * *$ & $* * *$ \\
\hline Sexual Activity & - & * & $* * *$ & * & - & - & $* *$ & $* *$ & - & * & - & - \\
\hline Tobacco Use & $* * *$ & $*$ & $* * *$ & $* * *$ & $* * *$ & $* *$ & $* * *$ & ** & $* *$ & $* * *$ & $*$ & $* *$ \\
\hline Drug Use & $* * *$ & - & $* * *$ & $* * *$ & $*$ & $* * *$ & * & $* *$ & $* *$ & $* * *$ & $* * *$ & - \\
\hline Alcohol Use & $* *$ & - & $* * *$ & - & $* * *$ & - & $* *$ & $* *$ & $* * *$ & $* *$ & $* * *$ & - \\
\hline School Suspension & - & - & $* *$ & - & $* *$ & - & $*$ & - & $*$ & * & $* * *$ & - \\
\hline Physical Fighting & - & - & $* * *$ & - & * & * & $* *$ & $* * *$ & $* *$ & - & ** & - \\
\hline Grades & $* * *$ & $* * *$ & $* * *$ & $* *$ & $* * *$ & $* * *$ & $* * *$ & $* * *$ & $* * *$ & $* * *$ & $* * *$ & $* * *$ \\
\hline
\end{tabular}

$*=\mathrm{p}<.05 \quad * *=\mathrm{p}<.01 \quad * * *=\mathrm{p}<.001$

As can be seen from these results, the general trend is for strong levels of PYD to be associated with lower levels of risk behaviors and higher levels of positive, healthy behaviors. The relationship varies by health area and PYD component. While all six PYD indicators are strong predictors for physical activity, nutrition, tobacco use and grade performance, the indicators vary in how well they predict the remaining risk behaviors. In turn, this variation suggests that each component captures a fairly different aspect of PYD. Taken together, all six indicators are important predictors of risk health behaviors, as expected.

\section{Creating and adopting a PYD state benchmark measure}

Following the preliminary analysis of the six PYD questions, our goal was to create a state benchmark measure, based on all 6 questions, that could be used to track changes in PYD across time and set programmatic and policy goals. We created three alternative versions of the PYD benchmark measure. In all 3 versions, we included only students that answered all 6 questions ( $n=4,803$ students). We addressed the concern of excluding from the analysis those students in the sample that did not answer all 6 questions (a total of 1,414 ) by looking at non-responder data. Over $80 \%(1,135)$ of those that answered fewer than 6 questions actually answered only 2 questions (the two questions that are in the beginning of the survey, about physical and emotional health). Thus, even if we were to include in the analysis students that answered at least half of the questions, we would not be adding a substantial number of observations. We also compared the risk behaviors of students that we excluded in the calculation of the benchmarks (because they did not answer all 6 questions) to those of the students we included in the analysis. We found no significant differences in the areas of nutrition, tobacco, alcohol use or grade performance. For the remaining six risk behavior areas, 
we found small differences but in opposite directions: students excluded in the analysis were somewhat more likely to use drugs, fight and be suspended from school, but also more likely to be physically active and less likely to consider suicide or be sexually active. Thus there are no systematic risk behavior differences between students included in the analysis and those excluded that would bias our estimates.

Versions 1 and 2 rely on counting the number of PYD questions that students answered "positively"; positive answers were: "excellent", "very good", "good", "very much true" and "pretty much true". Version 3 calculated the mean PYD score for the student population by treating the answers to the 6 questions as interval scales, and dividing students in two categories: those with "strong" levels of PYD (above average) and those with "weak" levels of PYD (below average).

\section{Benchmark Versions}

Version 1: The percent of students that answered at least 4 out of 6 PYD questions positively is the percent of students with strong PYD levels.

Version 2: The percent of students that answered at least 5 out of 6 PYD questions positively is the percent of students with strong PYD levels.

Version 3: The percent of students that rank above the population PYD mean is the percent of students with strong PYD levels.

Version 1 of the benchmark measure codes $84 \%$ of $8^{\text {th }}$ graders and $87 \%$ of the $11^{\text {th }}$ graders as having strong PYD levels. These high percentages leave little opportunity to formulate a policy recommendation to increase the percent of students with strong levels of PYD. Versions 2 and 3 of the benchmark measure are less inclusive and quite consistent with each other. $84 \%$ of the students are coded the same way in both versions (as either having "strong" or "weak" levels of PYD). Figure 6 presents the distribution of students according to PYD levels, for each of the three versions.

Figure 6

Distribution of students by PYD rating in the three alternative benchmark measures

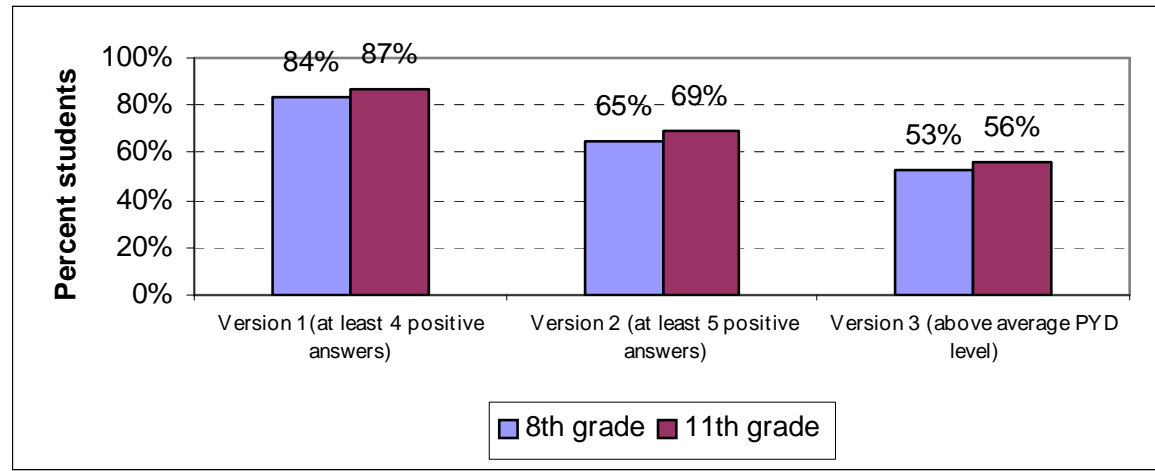

All three versions of the benchmark measures were tested against the selected risk areas, obtaining similar results as when we tested each question separately against respective risk areas. 
Table 4

Levels of Statistical Significance for the Relationship between PYD and Health Risk Behaviors for the three Alternative Benchmark Measures

\begin{tabular}{|c|c|c|c|c|c|c|}
\hline & \multicolumn{2}{|c|}{$\begin{array}{c}\text { Benchmark Version } 1 \\
\text { (at least } 4 \text { positive answers) }\end{array}$} & \multicolumn{2}{|c|}{$\begin{array}{c}\text { Benchmark Version } 2 \\
\text { (at least } 5 \text { positive answers) }\end{array}$} & \multicolumn{2}{|c|}{$\begin{array}{c}\text { Benchmark Version } 3 \\
\text { (PYD score above average) }\end{array}$} \\
\hline & 8th & 11th & 8th & 11th & 8th & 11th \\
\hline Nutrition & $* *$ & $*$ & $* * *$ & $* * *$ & $* * *$ & $* * *$ \\
\hline Physical Activity & $* * *$ & $* * *$ & $* * *$ & $* * *$ & $* * *$ & $* * *$ \\
\hline Suicide & $* * *$ & $* * *$ & $* * *$ & $* * *$ & $* * *$ & $* * *$ \\
\hline Sexual Activity & $* *$ & - & $* * *$ & $* *$ & $* * *$ & - \\
\hline Tobacco Use & $* * *$ & $* * *$ & $* * *$ & $* * *$ & $* * *$ & $* * *$ \\
\hline Drug Use & $* * *$ & $* * *$ & $* * *$ & $* * *$ & $* * *$ & $* * *$ \\
\hline Alcohol Use & $* * *$ & $*$ & $* * *$ & $* *$ & $* * *$ & * \\
\hline $\begin{array}{c}\text { School } \\
\text { Suspension }\end{array}$ & $* * *$ & $* * *$ & $* *$ & - & $* * *$ & - \\
\hline Physical Fighting & $* * *$ & - & $* * *$ & - & $* * *$ & - \\
\hline Grades & $* * *$ & $* * *$ & $* * *$ & $* * *$ & $* * *$ & $* * *$ \\
\hline
\end{tabular}

$*=\mathrm{p}<.05 \quad * *=\mathrm{p}<.01 \quad * * *=\mathrm{p}<.001$

Overall, our analysis of the alternative benchmarks revealed that all three were consistently confirming the same strong relationship linking high levels of PYD to low levels of risk behaviors and high levels of positive health behaviors. All three benchmark variables measure PYD well.

However, because version 1 of the benchmark (at least 4 positive answers) leaves little room to recommend a targeted increase in the percentage of students with high levels of PYD (since already over $80 \%$ of students qualify as having strong PYD levels under this construct), we eliminated this measure. Because version 3 relies on treating interval answer scales as ordinal (assigning numerical values and assuming that the distances between answer alternatives are equal), which is somewhat controversial, we also eliminated this version. However, version 3 is very consistent with version 2, which adds validity to version 2 as the final choice of the PYD benchmark measure - the percentage of students answering at least 5 PYD questions positively.

After completing analysis of the three versions and selecting version 2, the wording of the benchmark was finalized. The PYD state benchmark is: "Percent of teens who report positive youth development attributes; a) $8^{\text {th }}$ grade; b) $11^{\text {th }}$ grade."

A noteworthy additional finding is that, in those risk areas where one gender is typically more at risk, gender differences diminish or fully disappear for students with low PYD levels. For instance, in the areas of physical activity and suicide, females are typically more at risk than males - but these gender differences dissipate for students with the lowest levels of PYD. When it comes to suspension from school, getting involved in physical fights, and grades, males are more at risk than females, but again these gender differences diminish or even disappear for students with low levels of PYD. 
Figure 7 below provides an illustration using the distribution of students by gender for $8^{\text {th }}$ graders contemplating suicide. As can be seen from the graph, for both males and females, the higher the level of PYD, the lower the proportion of students contemplating suicide. Females are at higher risk than males, with the exception of students with bottom levels of PYD - 2 or less PYD questions answered positively. In fact, for students that answered more than 3 PYD questions positively, the differences between males and females are highly significant $(p<.001)$; but for students that answered 2 or less PYD questions positively, the differences in gender are no longer significant. Thus, low levels of PYD affect strongly both females and males and diminish or fully eliminate gender differences in the likelihood to incur risky behaviors.

Figure 7

PYD and considering suicide, for $8^{\text {th }}$ grade females and males

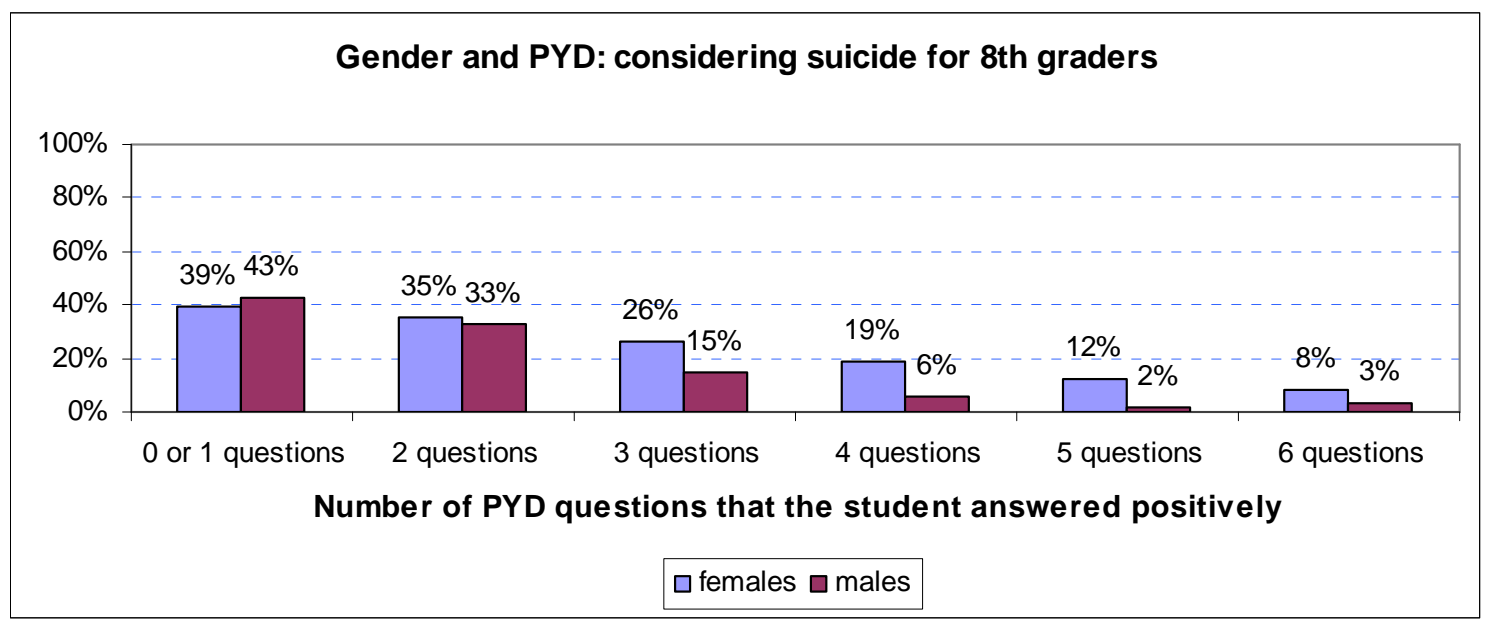

\section{Policy Implications}

The findings on the relationship between our PYD benchmark and prevalence of adolescent risk behaviors have implications for policy development at two levels: state government and local involvement (primarily, school and community organizations). At the level of state government, the findings have reinforced the goals of the Oregon Commission on Children and Families project. These goals aim to increase PYD through adoption of state agency policies that support PYD principles and changes in service delivery systems, involvement of youth in service learning, engagement of youth in local and state government, and providing professional development to public and private community partners that serve youth. Adoption of the PYD benchmark formalizes the state's commitment to PYD and elevates it to a level of state agency discourse making the policy recommendations related to PYD advanced by the Commission more relevant.

Now that a benchmark has been established, the State will continue to follow and track data as it comes in annually to see how Oregon youth are progressing, thus creating a long-term commitment and increasing public recognition of PYD as a component of measuring the health and wellbeing of Oregon youth. In addition, Oregon will be monitoring closely at the state level to observe changes across time in the relationship between our benchmark and risk behaviors. Perhaps most significantly, establishing this benchmark and its significance raises the possibility of determining funding priorities based on the benchmark. State benchmarks are often one of the justifications used for increasing activities or allocating state resources/funding to specific 
programs. The presence of a PYD Benchmark now allows for programs that demonstrate effectiveness in targeting elements of PYD (competence, confidence, health status, etc.) to link their funding requests directly to their efforts to strengthen PYD.

At the school and community levels, these findings offer support for programs that target youth and again aim to boost one or more elements of PYD in order to reduce risk behaviors and promote positive health behaviors and attitudes. Programs such as Oregon Mentors (where mentoring is an evidence-based strategy) that promote youth character, confidence and caring relationships with adults, are among those that should find the most support in these findings. Another prime example is the youth-created Youth Bill of Rights in Portland, a process that engaged thousands of young people in focus groups, surveys and other community engagement methods.

Based on the benchmark development and findings, communities and schools will be able to conduct needs assessments to evaluate their PYD efforts as they relate to the elements of the benchmark and risk behaviors. All secondary schools that participate in the Oregon Healthy Teens survey receive school-level data, which will allow them to calculate their own benchmark percentage and thus set programmatic goals for positive youth programs. Under some circumstances, it may also be feasible for schools or other community-based programs that work with youth to utilize one or more of the PYD indicator questions, or the full PYD measure, as part of an evaluation of their program.

Across the spectrum, the Oregon PYD findings should be encouraging to those who are working on developing or implementing positive youth programs. Of course, the fact that a strong relationship exists between PYD and risk behaviors does not necessarily imply a one-way relationship. Various social, environmental, biological and developmental factors all influence the prevalence of substance use, physical and emotional health, sexual activity and other areas of health risk. Programmatic solutions cannot exist in a vacuum if they hope to be effective. However, programs that improve connectedness to caring adults, aim to boost youth feelings of confidence, impart social, decisional and problem-solving skills that raise youth competence levels, or promote meaningful community engagement and involvement now benefit from additional evidence in their relationship to reduced risk behaviors.

\section{Conclusion}

There are many options to consider when applying a multi-faceted concept such as positive youth development to real world public policy. This effort shows the feasibility of using an existing mechanism (Oregon Healthy Teens survey) to first define, then to measure PYD against reported risk behaviors among youth. Key to the success of this endeavor was multi-agency collaboration in measure design and identifying resources and capacity to analyze and test underlying assumptions. Collaboration was also essential in assuring the availability of an established state-level benchmark system to anchor the measure and a consensus process for final determination on how the benchmark would be established and portrayed. As expected, youth that scored higher on PYD measures were less likely to report engaging in risk behaviors and more likely to have higher self-reported grades. This project offers an approach and methodology to develop a state-level PYD measure, encourages further support for initiatives and programs that target PYD elements, and strengthens policy arguments for the continuation and funding of such programs. 


\section{References}

Alaska Division of Public Health. (2006). Alaska Health Status Indicators: 1996 - 2005.

Retrieved October 24, 2007 from http://hss.state.ak.us/hspc/files/HealthStatus2006.pdf.

Benson, P.L., Scales, P.C., Hamilton, S.F., et al. (2006). Positive youth development so far: core hypotheses and their implications for policy and practice. Search Institute Insights \& Evidence, 3, 1-13.

Bernat, D.H. \& Resnick, M.D. (2006). Healthy youth development: science and strategies. Journal of Public Health Management Practice, 12, S10-S16.

Boles, S., Biglan, A., \& Smolkowski, K. (2006). Relationships among negative and positive behaviours in adolescence. Journal of Adolescence, 29, 33-52.

Carter, T.P., Spitalny, K.C., Marsh, N.R., et al. (2006). Comprehensive statewide approach to improve youth outcomes: experience of the New York State youth development team. Journal of Public Health Management Practice, 12, S32-S40.

Catalano, R.F., Berglund, M.L., Ryan, J.A.M., et al. (2004). Positive youth development in the United States: research findings on evaluations of positive youth development programs. In Peterson C, ed., Positive development: realizing the potential of youth (98-124). Thousand Oaks, Ca: The American Academy of Political and Social Science.

Coie, J.D., Watt, N.F., West, S.G., et al. (1993). The science of prevention: a conceptual framework and some directions for a national research program. American Psychologist, 48, 1013-1022.

Hawkins, J.D., Catalano, R.F., \& Miller, J.Y. (1992). Risk and protective factors for alcohol and other drug problems in adolescence and early adulthood: implications for substance abuse prevention. Psychological Bulletin, 112(1), 64-105.

Johnston, B., Wheeler, L., Deuser, J., et al. (2000). Outcomes of the Kaiser Permanente TeleHome Health Research Project. Archives of Family Medicine, 9, 40-45.

Metzler, M. (2006). Community Health Status Indicators Project. Retrieved October 24, 2007 from http://cdc.gov/nceh/tracking/webinars/jul06/MetzlerWebinar072406.pdf. National Center for Chronic Disease Prevention and Health Promotion, Division of Adult and Community Health, Centers for Disease Control.

Nicholson, H.J., Collins, C., \& Holmer, H. (2004). Youth as people: the protective aspects of youth development in after-school settings. Annals of the American Academy of Political and Social Science, 591, 55-71.

Oregon Department of Administrative Services. (2002). Oregon Progress Board Recognized for Innovation in Public Sector. Press Release downloaded from http://egov.oregon.gov/DAS/docs/4-9-02-progressbdinnovation.pdf. 
Resnick, M.D., Bearman, P.S., Blum, R.W., et al. (1997). Protecting adolescents from harm: findings from the National Longitudinal Study of Adolescent Health. Journal of the American Medical Association, 278, 823-832.

Resnick, MD, Harris LJ, \& Blum, RW. (1993). The impact of caring and connectedness on adolescent health and well-being. Journal of Paediatric \& Child Health, 29(suppl1), S3-S9.

Roth, J.L. \& Brooks-Gunn, J. (2003). What exactly is a youth development program? Answers from research and practice. Applied Development Science, 7, 194-211.

Roth, J., Brooks-Gunn, J., Murray, L., \& Foster, W. (1998). Promoting healthy adolescents: synthesis of youth development program evaluations. Journal of Research on Adolescence, 4, 423-59.

Sabaratnam, P. \& Klein, J.D. (2006). Measuring youth development outcomes for community program evaluation and quality improvement: findings from dissemination of the Rochester Evaluation of Asset Development for Youth (READY) tool. Journal of Public Health Management Practice, 12, S88-S94.

Scales, P.C., Benson, P.L., \& Mannes, M. (2006). The contribution to adolescent well-being made by nonfamily adults: an examination of developmental assets as contexts and processes. Journal of Community Psychology, 34, 401-13.

Surko, M., Pasti, L.W., Whitlock, J., et al. (2006). Selecting statewide youth development outcome indicators. Journal of Public Health Management Practice, 12, S72-78.

Werner, EE \& Smith, RS. (1977). Kauai's Children Come of Age. Honolulu: University of Hawaii Press.

(C) Copyright of Journal of Youth Development Bridging Research and Practice. Content may not be copied or emailed to multiple sites or posted to a listserv without copyright holder's express written permission. However, users may print, download or email articles for individual use. 